Article

\title{
RGB Image-Derived Indicators for Spatial Assessment of the Impact of Broadleaf Weeds on Wheat Biomass
}

\author{
Christelle Gée ${ }^{1, *(D)}$ and Emmanuel Denimal ${ }^{2}$ (D) \\ 1 Agroécologie, AgroSup Dijon, INRAE, Univ. Bourgogne, Univ. Bourgogne Franche-Comté, \\ F-21000 Dijon, France \\ 2 AgroSup Dijon, Service Système d'Information Appui à la Recherche et Enseignement Supérieur, \\ 26 Bd Dr Petitjean, 21000 Dijon, France; emmanuel.denimal@agrosupdijon.fr \\ * Correspondence: christelle.gee@agrosupdijon.fr
}

Received: 23 June 2020; Accepted: 10 September 2020; Published: 14 September 2020

\begin{abstract}
In precision agriculture, the development of proximal imaging systems embedded in autonomous vehicles allows to explore new weed management strategies for site-specific plant application. Accurate monitoring of weeds while controlling wheat growth requires indirect measurements of leaf area index (LAI) and above-ground dry matter biomass (BM) at early growth stages. This article explores the potential of RGB images to assess crop-weed competition in a wheat (Triticum aestivum L.) crop by generating two new indicators, the weed pressure (WP) and the local wheat biomass production $(\delta \mathrm{BMc})$. The fractional vegetation cover $(\mathrm{FVC})$ of the crop and the weeds was automatically determined from the images with a SVM-RBF classifier, using bag of visual word vectors as inputs. It is based on a new vegetation index called MetaIndex, defined as a vote of six indices widely used in the literature. Beyond a simple map of weed infestation, the map of WP describes the crop-weed competition. The map of $\delta \mathrm{BMc}$, meanwhile, evaluates the local wheat above-ground biomass production and informs us about a potential stress. It is generated from the wheat FVC because it is highly correlated with LAI $\left(r^{2}=0.99\right)$ and BM $\left(r^{2}=0.93\right)$ obtained by destructive methods. By combining these two indicators, we aim at determining whether the origin of the wheat stress is due to weeds or not. This approach opens up new perspectives for the monitoring of weeds and the monitoring of their competition during crop growth with non-destructive and proximal sensing technologies in the early stages of development.
\end{abstract}

Keywords: weed pressure; crop-weed competition; machine learning; vegetation index; visible images; SVM-RBF classification

\section{Introduction}

The emergence of proximal sensing technologies in precision agriculture provides new opportunities to drastically reduce chemical herbicides from site-specific weed management (SSWM) while maintaining production yield, quality, and commercial value [1-3]. Although weed management in field crops is a long story [4,5], it is still topical [6-8]. The development of affordable and easy to use unmanned aerial vehicles (UAV) allows accurate weed monitoring thanks to high resolution images [9-11]. Imaging systems are mostly based on multi or hyperspectral optical sensors. They require complex image processing algorithms to discriminate between crops and weeds and to generate weed maps [11-13]. The first step consists of extracting vegetation pixels in the image. The remote sensing community developed spectral indices to quantify greenness in a multispectral image [14-16]. The segmentation is generally performed using vegetation indices built as a combination of spectral bands. Their choice depends on the application: for RGB images, the most common is the excess green 
index (ExG or 2g-r-b index) proposed by Woebbecke et al. [14]. When the near infrared band is available, the normalized difference vegetation index (NDVI) is a classic [17]. Tang et al. [18] highlighted the pros and cons of color indices for plant-background segmentation. With aerial images captured from an UAV, Torres-Sanchez et al. [15] demonstrated that, among different vegetation indexes, the ExG and VEG indices performed best in vegetation fraction mapping. Our study focuses on the MetaIndex, a new vegetation index that takes advantage of six common indices.

Several image classifiers based on machine learning have been successfully applied to classify plants and to identify weed species [19-22]. The recent development of high resolution UAV imagery [20,23-25] allowed fast and accurate crop weed recognition. Depending on the crop (wheat, sunflower, maize ... ) and the weed, these algorithms lead to 75-95\% classification accuracy. Pérez-Ortiz et al. [25] compared several classification algorithms on multispectral images (six wavebands) acquired by UAV over sunflower at three flight altitudes. They demonstrated that, regardless of the method, the higher the resolution of the images, the better the results. Peña et al. [9] applied an object-based image analysis (OBIA) to generate weed infestation maps from UAV imagery. They could discriminate three categories of weed coverage in maize crops with $86 \%$ overall accuracy. Using convolutional neural network (CNN), Huang et al. [12] were able to differentiate rice from unspecified weeds, with $97 \%$ accuracy. Bah et al. [26] developed a new automatic learning method also based on CNN for weed detection in UAV images, with an unsupervised training dataset. Support vector machine (SVM) are powerful supervised learning classifiers to discriminate vegetation in a complex case, e.g., overlapping leaves. Pérez-Ortiz et al. [20] used SVM to classify crop/weed from RGB images in sunflower and maize fields. Suh et al. [27] compared different machine learning classifiers to differentiate sugar beet from volunteer potato plants, concluding that SVM was more efficient than random forest or neural networks. Pflanz et al. [8] could discriminate between wheat and weeds with 98\% accuracy and differentiate various weed species with $87 \%$ accuracy. Thus, weed mapping is a major issue to provide decision-making support for variable rate spraying application [28,29]. However, due to the reduction of chemical inputs and to climate change, particular attention should be given to a regular and precise monitoring of crop growth [30,31]. Indeed, the emergence of crop stressors can negatively impact on plant development and ultimately crop productivity [31,32]. Therefore, maintaining weed flora below a nuisance threshold by non-destructive measurements is a major challenge for spatio-temporal crop and weed monitoring. Early monitoring of crop- weed competition is essential to develop new control strategies of weed emergence and anticipate their management. Competition indicators are generally based on density measurements or visual plant recognition, which are time-consuming and labor-intensive for farming practices. Other parameters such as dry matter biomass (BM) and leaf area index (LAI) can be measured by destructive methods, also time-consuming [33-35]. Recent research revealed that the BMw/BMc ratio could express crop-weed competition [36]. Non-destructive methods based on optical imaging devices may be powerful to study weed competition and monitor wheat growth, especially at early growth stages. Several articles [37-39] report indirect estimation of BM and LAI using vegetation indices and spectral analysis [40-43] by determining the proportion of ground occupied by vegetation (i.e., vegetation cover, vegetation fraction or fractional vegetation cover, fraction of green cover). Thus, digital image approaches became an alternative solution to infer plant biomass $[39,44]$, especially at early growth stages. They allow monitoring plants over time for crop protection management.

This article aims to evaluate the origin of wheat stress while looking at weed infestation using RGB images. The first part describes the acquisition of data on three different dates. Then we present the image-processing algorithm for crop/weed discrimination and introduce a new vegetation index called MetaIndex. The calibration between destructive (LAI and BM) and non-destructive (FVC) measurements deduced from an in-field image acquisition system is investigated. In a second part, two new non-destructive indicators are generated to evaluate the weed pressure (WP) and the local evaluation of wheat biomass production on wheat growth $(\delta \mathrm{BMc})$ informing about a potential stress. 


\section{Materials and Methods}

\subsection{Study Site and Data Acquisition}

The study site is located in Dijon, Burgundy, France $\left(47^{\circ} 18^{\prime} 32^{\prime \prime} \mathrm{N}, 5^{\circ} 04^{\prime} 0.165^{\prime \prime} \mathrm{E}\right)$. The experiment was conducted in 2018 during the early stages of winter wheat (Triticum aestivum L.) growth, from the 3-leaf stage to tillering on three sampling dates: 23 March, 6 April, and 12 April 2018. No nitrogen nor weed management was applied. The weed flora is composed of annual dicots such as Polygonum aviculare L. (EPPO code: POLAV), Fallopia convolvulus L. (POLCO), Capsella bursa-pastoris (L.) Medicus (CAPBP) and perennial dicots such as Convolvulus arvensis L. (CONAR). These plants are not representative of wheat crops. The emergence of unspecific weeds reveals the history of the plot and the agricultural practices (previous crop and tillage). The Apache cultivar was sown on 12 November 2017 on a chalky-clay deep soil with a density of $345 \mathrm{~g} \cdot \mathrm{m}^{-2}$. The plot $\left(1.2 \mathrm{~m} \times 15 \mathrm{~m}=18 \mathrm{~m}^{2}\right)$ was composed of seven crop rows separated by a distance of $0.15 \mathrm{~m}$ (Figure 1a). It was divided into three subplots associated to each sampling date. Destructive measurements, sample collection (wheat and weeds), and RGB image acquisition were performed in each quadrat $\left(\mathrm{S}=0.45 \mathrm{~m} \times 0.76 \mathrm{~m}=0.342 \mathrm{~m}^{2}\right)$. There were three replicates per date.

(a)

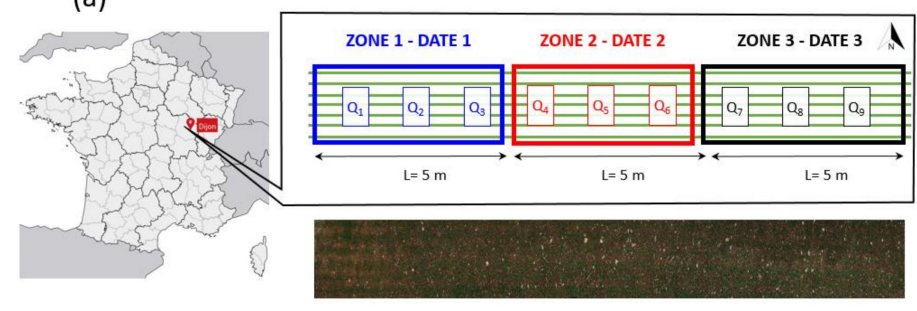

(b)

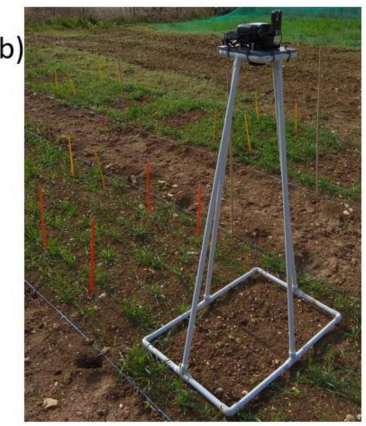

Figure 1. (a) Winter wheat field in Dijon, Burgundy, France; (b) Movable sensing platform equipped with a digital RGB camera and an automated triggering system.

The destructive measurements served as a reference. The aerial parts of the wheat and the weeds were collected separately and were packed into paper bags. We measure the leaf area index (LAI expressed in $\mathrm{m}^{2} \cdot \mathrm{m}^{-2}$ ) using a planimeter. Then, for each sampling date, the above-ground dry matter biomass (BM, g.m ${ }^{-2}$ ) was determined by weighing plants, after being oven dried at $80{ }^{\circ} \mathrm{C}$ for $48 \mathrm{~h}$.

In parallel, we built a movable sensing platform made of PVC pipes, on which a Canon EOS 450D (Canon Inc., Tokyo, Japan) commercial digital camera was mounted at a height of $1 \mathrm{~m}$ (Figure $1 \mathrm{~b}$ ). Capturing vertical images allows comparing the results with LAI at early growth stages. The main parameters of the camera are described in Table A1 (Appendix A). The camera shutter was controlled remotely. Each experiment was conducted in clear weather under stable light conditions. The exposure time and shutter speed were optimized for the light conditions. The RGB images have a spatial resolution of $0.2 \mathrm{~mm} /$ pixel. Images were acquired before sampling the plants. For each measure, two images are shot: one before plant sampling and containing both the wheat and weed populations, and another after the wheat plants were removed, therefore, containing only weeds. Outside the sampling and measurement areas, six images of wheat were taken this way. These images labelled "weeds" and "wheat" will be used, after being transformed into thousands of thumbnail images to feed the classifier during the training phase. In total, 18 images were recorded at several plant growth stages listed in Table 1.

On the first date only, the whole surface of the plot was imaged. As for a UAV platform, we built an orthomosaic photo of the entire plot with a $\sim 60 \%$ overlap between successive images and a $\sim 40 \%$ overlap between passes. We used Image Composite Editor (Version 2.0.3.0, 2015, Microsoft Corporation, Redmond, WA, USA), an image stitcher software, to create a panoramic image. 
Table 1. Acquisition dates, image dataset and wheat growth stages.

\begin{tabular}{|c|c|c|c|c|}
\hline Date & $\begin{array}{l}\text { Zadoks Growth Stage } \\
\text { and Development Phase } \\
\text { (3-Leaf Stage) }\end{array}$ & RGB Images & $\begin{array}{c}\text { Destructive Measurements } \\
\text { (Plant Identification, LAI } \\
\text { and Dry Biomass for Crop } \\
\text { and Weed) }\end{array}$ & Comments \\
\hline 23 March 2018 & GS22 & $\begin{array}{c}254 \text { images on } \\
3 \text { quadrats } \\
\left(Q_{1}, Q_{2}, Q_{3}\right)\end{array}$ & $\begin{array}{l}3 \text { quadrats: } \\
\mathrm{Q}_{1}, \mathrm{Q}_{2}, \mathrm{Q}_{3}\end{array}$ & \multirow{4}{*}{$\begin{array}{c}\text { critical period for } \\
\text { weed-crop competition }\end{array}$} \\
\hline $\begin{array}{l}\text { Leaf and Tiller } \\
\text { Development }\end{array}$ & Middle-tillering & & & \\
\hline 6 April 2018 & GS24 & $\begin{array}{c}3 \text { images on } \\
3 \text { quadrats } \\
\left(Q_{4}, Q_{5}, Q_{6}\right)\end{array}$ & $\begin{array}{l}3 \text { quadrats: } \\
\mathrm{Q}_{4}, \mathrm{Q}_{5}, \mathrm{Q}_{6}\end{array}$ & \\
\hline $\begin{array}{l}\text { Leaf and Tiller } \\
\text { Development }\end{array}$ & End-tillering & & & \\
\hline $\begin{array}{l}12 \text { April } 2018 \\
\text { Stem extension }\end{array}$ & $\begin{array}{c}\text { GS30 } \\
\text { Stem-elongation }\end{array}$ & $\begin{array}{l}3 \text { images on } \\
3 \text { quadrats } \\
\left(Q_{7}, Q_{8}, Q_{9}\right)\end{array}$ & $\begin{array}{l}3 \text { quadrats: } \\
\mathrm{Q}_{7}, \mathrm{Q}_{8}, \mathrm{Q}_{9}\end{array}$ & $\begin{array}{c}\text { Good nutrient and water } \\
\text { supply are determining } \\
\text { yield potential }\end{array}$ \\
\hline
\end{tabular}

\subsection{Image Processing}

Figure 2 illustrates the flowchart of the methodology used to generate output maps to assess crop-weed competition. After the data collection (step A), the image processing (step B) determines the fractional vegetation cover $(\mathrm{FVC})$ of both the wheat $(\mathrm{FVCC})$ and the weeds $(\mathrm{FVCw})$. It is defined as the ratio of the number of pixels of vegetation (crop vs. weeds) to the total number of pixels in the image. Then, a correlation is established between FVCC and BMc to map wheat biomass. In step C, information about the effect of weed on wheat crop is provided by two non-destructive image-derived indicators: the weed pressure (WP) and the wheat biomass production, $\delta \mathrm{BMc}$.

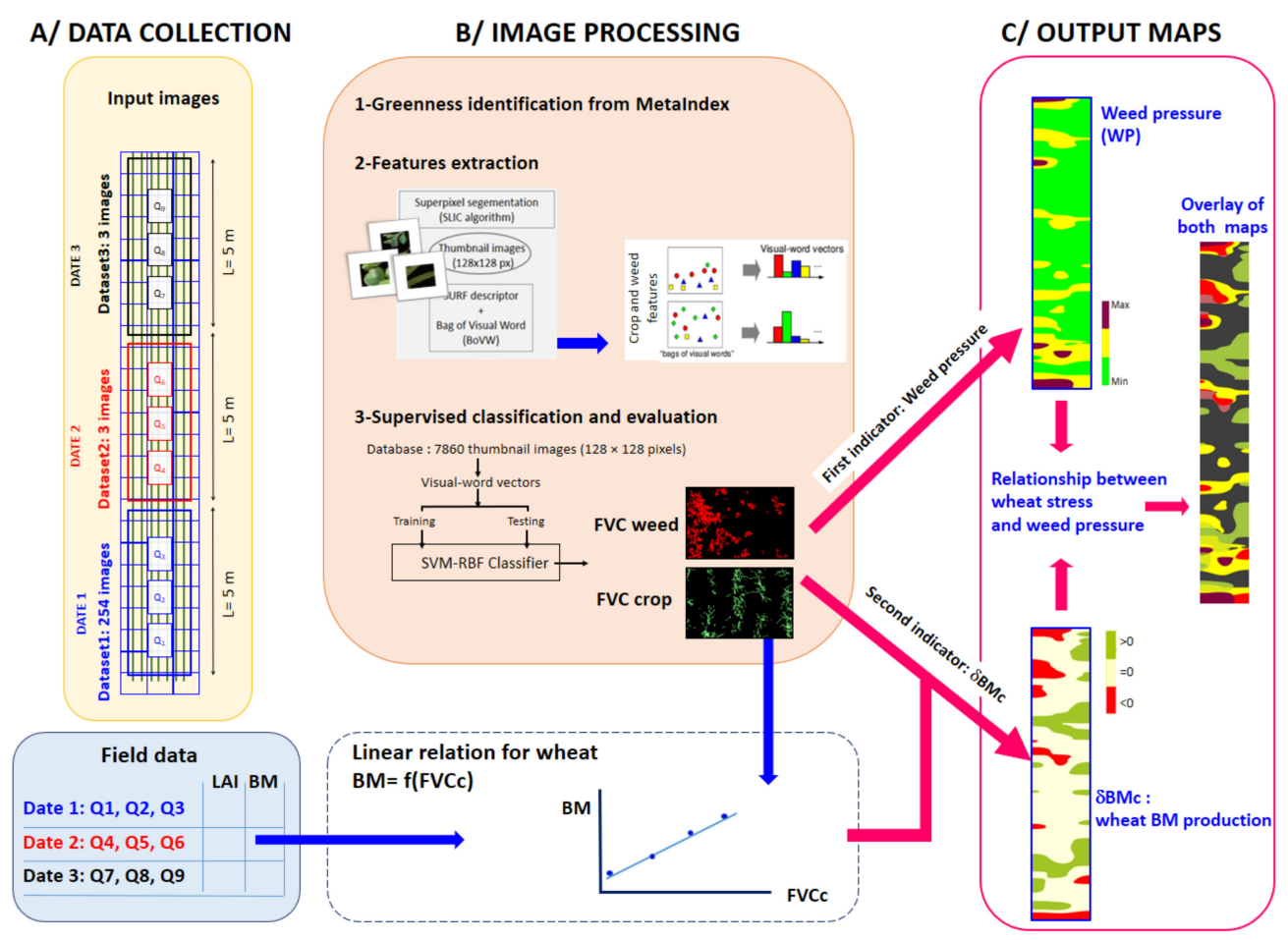

Figure 2. Methodological framework with the three main steps: data acquisition (A), image processing and classification results (B), and output maps (FVC: fractional vegetation cover, WP: weed pressure and $\delta$ BMc: wheat above-ground biomass production) to monitoring the impact of weed on wheat growth $(\mathbf{C})$. 
The image processing (step B) pipeline can be summarized in four steps: (1) segmentation of the initial RGB image to create a vegetation image from a MetaIndex; (2) feature extraction from bag of visual word (BoVW) descriptors using superpixels of vegetation; and (3) supervised classification from support vector machine (SVM) to discriminate crop from weeds.

All the image pre-processing and processing algorithms were implemented in Matlab (Version 2016b, The Mathworks, Natick, MA, USA).

Greenness identification from MetaIndex (step B-1). We propose the new vegetation index called MetaIndex, which combines the advantages of six vegetation indices (Table 2) commonly used in the literature and recently reported in Baniaich et al. [45], Meyer et al. [16], Guo et al. [46], and Yang et al. [47]. It consists in assigning a pixel to a class (vegetation or other) by a majority vote performed on four indices over the six listed in Table 2. This method is completed by a geodesic segmentation to refine the results and obtain a $B \& W$ vegetation image also called $B \& W$ vegetation mask (white pixel for the vegetation, black for the background).

Table 2. Names and formulas of the six vegetation indices used to build the MetaIndex.

\begin{tabular}{cc}
\hline Vegetation Index & Formula \\
\hline ExG: Excess Green [14,45] & ExG $=2 g-r-b$ \\
\hline MExG: Modified Excess Green $[47,48]$ & MExG $=-0.884 r+1.262 g-0.311 b$ \\
\hline ExR: Excess Red [16,47] & ExR $=1.4 r-g$ \\
\hline CIVE: color index of vegetation extraction $[47,49]$ & CIVE $=$ \\
\hline VEG: vegetative index [45,50] & $0.441 r-0.811 g+0.385 b+18.787$ \\
\hline HSVDT: HSV (Hue Saturation Value) decision tree $[47]$ & $\begin{array}{c}\text { Set the hue value to zero if it is less than } 50 \text { or } \\
\text { greater than } 150: \text { H }((\mathrm{H}<50) \mid(\mathrm{H}>150))=0 ; \\
\text { Then use } \mathrm{T}=49 \text { as a threshold }\end{array}$ \\
\hline
\end{tabular}

Feature extraction (step B-2). The input data of the two-class SVM-RBF classifier is not the RGB image but a vector of main features specific to each class (crop vs. weed). Extraction of these features is quite complex and requires several image-processing steps. To reduce computation time, superpixels $(128 \times 128 \mathrm{px})$ are then created with the SLIC (Simple Linear Iterative Clustering) algorithm commonly used in the literature [26]. Combining a RGB image with its vegetation mask, only superpixels of vegetation are kept in the thumbnail images. We used the labelled ones to create the crop and weed training dataset (Figure 3). The SURF (speeded-up robust features) descriptor algorithm [51] allows extracting features $(\sim 1000)$ from these images. Thousands of variables are then extracted in each stand to construct a 500-dimensional BoVW vector, containing the most influential features $(\sim 500)$ owing the Bag of Visual World method [27,52,53]. This approach is very popular in agriculture to discriminate between crop and weeds $[8,27,51]$. With the labelled image database, the BoVW vector of each thumbnail is associated to a class, wheat or weeds. From this technique, we increase easily the number of labelled images of the training dataset.

Supervised classification and evaluation (step B-3). The classifier learns how to distinguish the crop from the weed flora (training phase). It is based on a support vector machine (SVM) algorithm [54] with a radial basis function (Gaussian type). Among all supervised techniques used for crop/weed discrimination, SVM-RBF is one of the most powerful classification algorithms based on machine learning $[8,11,21,23,25,55]$.

The learning dataset is made of 7860 thumbnails labelled into two classes: crop and weed. The classifier algorithm is calibrated from the learning set divided into a training set and a validation set. Labelled thumbnail images were randomly selected from the learning set with $85 \%$ for training and $15 \%$ for validation. Once the classification algorithm is validated, we test it with a new RGB image. Then a new BoVW vector is produced in relation to the codebook, and using the calibrated image 
classifier, the new BoVW vector is labelled as crop or weed. Finally we can build crop and weed maps, and calculate the respective fractional vegetation cover (FVC), FVCC and FVCw (Figure 2).

(a)

Crop class

(b)

Weed class
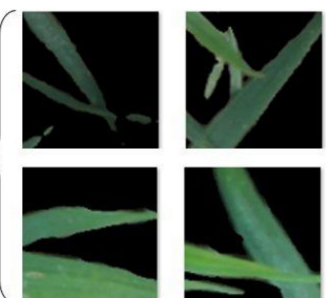
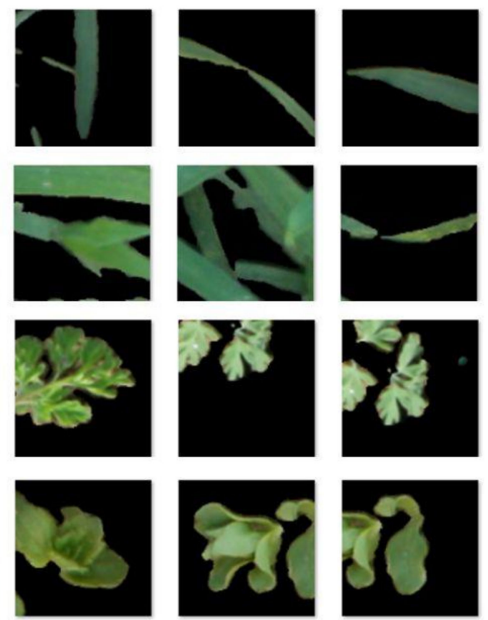
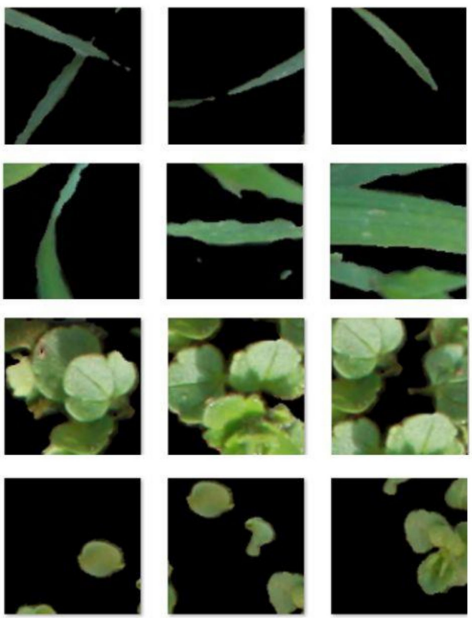

Figure 3. Sample thumbnail images for each class (weed and crop) used to create the training dataset: (a) Wheat; (b) Weeds. These thumbnails are extracted from the labelled image database built on different dates.

The calculation of specific statistical metrics derived from the confusion matrix [56] allows assessing the SVM-learning algorithm. Three metrics were computed for performance evaluation: Recall (Equation (1)) reflects the ability to reveal the needed information; Precision (Equation (2)) indicates the correctness of the detected results; F-score (Equation (3)) indicates the balance between Precision and Recall.

$$
\begin{gathered}
\text { Recall }=\frac{\mathrm{TP}}{\mathrm{TP}+\mathrm{FN}} \\
\text { Precision }=\frac{\mathrm{TP}}{\mathrm{TP}+\mathrm{FP}} \\
\mathrm{F}-\text { score }=\frac{2 \times \text { Recall } \times \text { Precision }}{\text { Precision }+ \text { Recall }}
\end{gathered}
$$

with TP being the number of true positives, FP and FN are the number of false positives and false negatives, respectively $[8,56]$.

\subsection{Two Non-Destructive Indicators for a Crop-Weed Competition}

Accurate monitoring of weeds while controlling wheat growth requires indirect measurements of leaf area index (LAI) and dry matter biomass (BM) at early wheat growth stage. Therefore, it is necessary to measure LAI and BM destructively to correlate them to FVCc. We developed two indicators deduced from the image. The weed pressure (WP) characterizes the relationship between crop and weed. For their growth, plants are in direct competition for water, nutrients and for light, main parameter at the end of winter. However, this indicator alone is not sufficient to conclude on the negative weed impact on wheat crop. The second indicator is a local above-ground biomass production, $\delta$ BMc. It provides information about stress but not about its cause. To check whether the stress originates from weeds or not, it has to be compared with the WP.

- $\quad$ The weed pressure (WP) is expressed as a percentage and defined as

$$
\mathrm{WP}=100 \times \mathrm{FVC}_{\mathrm{w}} / \mathrm{FVC}_{\mathrm{c}}
$$


with FVCw, the fractional weed vegetation cover, and FVCc, the fractional wheat vegetation cover. It provides information on the resource competition between the crop and the weeds: light, nutrients, and nitrogen. WP can be viewed as a substitute to the BMw/BMc ratio, which results from a destructive approach until the tillering stage by late winter.

- Evaluation of the local wheat above-ground biomass production: $\delta \mathrm{BMc}$

The objective of this second indicator is to observe locally the wheat biomass $\left(\delta \mathrm{BM}_{o b s}\right)$ and to compare it to a reference value $\left(\mathrm{BM}_{r e f}\right)$ from the image parameter, FVCc. It is defined as

$$
\delta \mathrm{BMc}=\mathrm{BM}_{r e f}-\mathrm{BM}_{o b s}
$$

with $\mathrm{BM}_{\text {ref }}$ being a reference value of above-ground wheat biomass considered as the average value of wheat above-ground biomass observed in the entire plot and $\mathrm{BM}_{o b s}$ the observed value of BMc.

This new indicator assessing the crop health is therefore deduced from FVCc at each location in the plot. It can take three values:

$1 / \delta \mathrm{BMc}<0$ may indicate an excess of biomass.

$2 / \delta \mathrm{BMc}=0$ indicates no health problem.

$3 / \delta$ BMc $>0$ may indicate a stress (i.e., pests, weeds or diseases) in wheat growth.

\section{Results}

\subsection{Crop/Weed Map from SVM Classifier and Classification Performance}

The input data of this supervised classification are the BoVW vectors that contain 500 features for each class. These vectors are built during the training phase with labelled thumbnail images automatically assigned as crop or weeds (Figure 3). The classification accuracy is quantified using a classical metric deduced from the confusion matrix. At the end, more than 7682-labelled thumbnails have been obtained, 3841 for the 'Wheat' class and 3841 for the 'Weeds' class (Table 3). Then the labelled dataset was randomly split into $85 \%$ training dataset and $15 \%$ testing dataset.

Table 3. Training and validation dataset in the wheat field.

\begin{tabular}{ccccc}
\hline Data & Class & $\begin{array}{c}\text { Training Thumbnails } \\
\text { Subset (85\%) }\end{array}$ & $\begin{array}{c}\text { Test Subset } \\
\mathbf{( 1 5 \% )}\end{array}$ & Total \\
\hline 9 images & Crop & 3264 & 577 & 3841 \\
9 images & Weed & 3264 & 577 & 3841 \\
18 images & All & 6528 & 1154 & 7682 \\
\hline
\end{tabular}

The SVM-RBF classifier is assessed from the confusion matrix (Table 4). The overall classification accuracy was 93\%, the Recall (also known as sensitivity) 94\%, and the Precision (also known as selectivity) 92\%. The F-score helps to measure Recall and Precision at the same time, and its value of $93 \%$, confirms that our classifier performed globally well in the crop/weed discrimination. Moreover, the high value of the Kappa coefficient $(\kappa=0.86)[57,58]$ also indicates that the SVM-RBF classifier correctly classified most of the objects. It encourages us to substitute image-derived parameters (FVC) for destructive measurements (LAI and BM).

Table 4. Confusion matrix of classification by the SVM-RBF classifier.

\begin{tabular}{ccccc}
\hline & & \multicolumn{3}{c}{ Actual } \\
\hline \multirow{3}{*}{ Predicted } & Wheat & Weed & Total \\
& Wheat & 543 & 47 & 590 \\
& Weed & 34 & 530 & 564 \\
& Total & 577 & 577 & 1154 \\
\hline
\end{tabular}




\subsection{Weed Pressure (WP)}

Figure 4 presents the results of image stitching over the whole plot $\left(18 \mathrm{~m}^{2}\right)$ on date 1 . The first map (Figure 4a) is a mosaic of 254 RGB images acquired in the field (Table 1). Then a black and white map of vegetation is obtained using the MetaIndex. Depending of the pixel position in the image, the method selects certain indices with a majority vote according to the illumination of the objects, which increases the robustness and sensitivity of this segmentation (Figure 5). At the end of the vote, a thresholding is carried out to provide a binary map of vegetation hereafter called the MetaIndex map (Figure $4 \mathrm{~b}$ ). The third map (Figure $4 \mathrm{c}$ ) is generated from the classification results using the SVM supervised learning classifier, which discriminates between the wheat and the weeds. In this plot, the weed infestation rate is $7.5 \%$. Finally, the WP map characteristic of the crop-weed competition is produced. It is obtained by a simple linear interpolation of the values at neighboring grid points is performed. This grid divides the plot into three subplots composed of 84,84 , and 86 rows respectively. A color map with three colors illustrates the in-field differences associated with high, medium, and low WP levels (Figure 4 d). On date 1, WP ranges from $3.37 \%$ to $20.63 \%$. Figure $4 \mathrm{c}$ shows that low pressure corresponds to $73.5 \%$ of the data (Figure A1). A few high intensity spots are observed, especially near the edge of the plot immediately adjacent to headlands (bottom, top and left side), except on the right side of the plot. The median equals $7.5 \%$ and the standard deviation 3\%. Figure A1 displays outliers that may originate from contamination by the unploughed headlands.
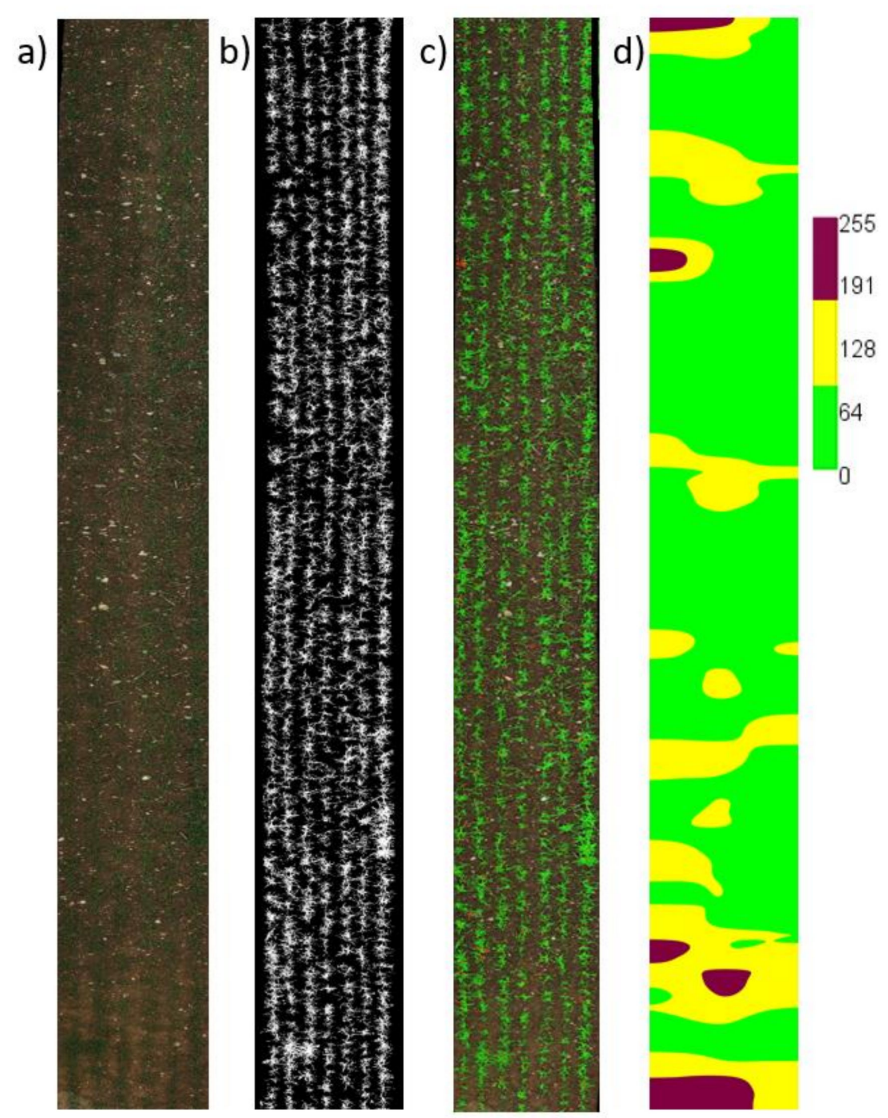

Figure 4. Four output maps on date 1: (a) Global RGB image of the field deduced from 254 images manually acquired; (b) Vegetation Image deduced from the MetaIndex; (c) Crop/weed discrimination using a SVM classifier (green=wheat, red=weed); (d) Weed pressure map. 


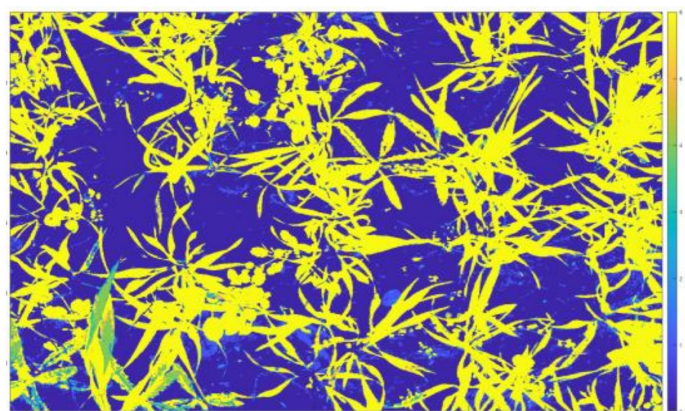

(a)

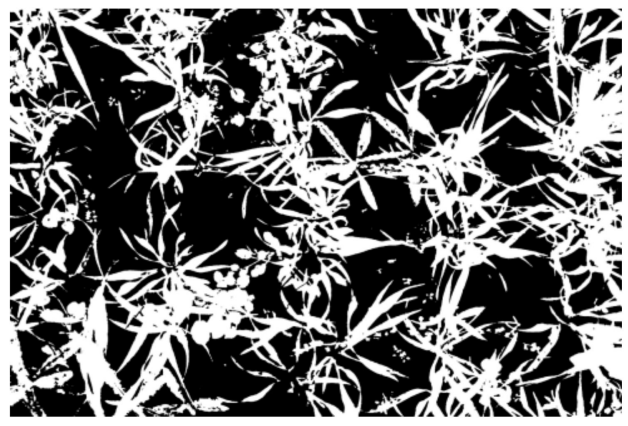

(b)

Figure 5. (a) Example of a MetaIndex image (Legend: blue $=0$ votes and yellow $=6$ votes); (b) Result after thresholding (white pixel for the vegetation and black for the background).

At this point, it is difficult to quantify the effect of WP on wheat health. One needs to interpret it with regard to the weed species diversity, abundance, and growth stage that may disturb crop growth $[59,60]$. The literature also shows that the early growth stages are also crucial in determining the intensity and outcome of subsequent crop-weed competition. In this experience, a high diversity of weed communities is observed at seedling stage of wheat (see Section 2.1). However, the dicot species observed are unusual but, according to the literature, they are little or moderately harmful to winter wheat [61-63]. Therefore, the WP values (Table A2 in Appendix A) obtained for the three quadrats on date 1 are $21.6 \%\left(\mathrm{Q}_{1}\right), 8.8 \%\left(\mathrm{Q}_{2}\right)$ and $14.1 \%\left(\mathrm{Q}_{3}\right)$. For each quadrat, six species have been observed with a density of 67 plants $/ \mathrm{m}^{2}$ (including $65.2 \%$ of Asteraceae and $22 \%$ of Brassicaceae), four with a density of 23 plants $/ \mathrm{m}^{2}$ (including $83.3 \%$ of Asteraceae), and six with a density of 76 plants $/ \mathrm{m}^{2}$ (including $65.5 \%$ of Asteraceae and $15.4 \%$ of Brassicaceae). In this case, it seems difficult to bring out a relationship between WP and weed species or density. This first indicator provides clear vision of the local weed impact on the crop. For a crop growth monitoring, however, it is important to connect WP with the crop health status.

\subsection{A Non-Destructive Indicator of Wheat Crop Growth: $\delta B M c$}

A non-destructive indicator of the local wheat crop growth $(\delta \mathrm{BMc})$ is produced based on indirect measurements of above-ground BM. Figure 6a presents the relation between destructive measurements of LAI and BM with FVCc. The prediction accuracy using a linear regression model is high. At the early stage of wheat growth, $\mathrm{BM}=176.86 \times \mathrm{FVC}_{\mathrm{C}}$ with $\mathrm{r}^{2}=0.93$ and LAI $=1.06 \times \mathrm{FVC}$ with $\mathrm{r}^{2}=0.99$. Our results obtained with the cultivar Apache are consistent with those obtained by Jeuffroy and Recous on the cultivar Soissons [64]. In their case, LAI was calculated daily from the total above-ground biomass finding that the ratio of leaf area to plant biomass (LA/BM) is constant $\left(6.10^{-3} \mathrm{~m}^{2} \cdot \mathrm{g}^{-1}\right)$ only for the beginning of the growth cycle and until LAI reached the value of four. Our value of 0.006 (LAI/BM $=$ 1.06/176.86) is consistent with this study and with others [65-68]. We demonstrate the relevance of the machine-learning algorithm (SVM-RBF classifier) to estimate the fractional wheat vegetation cover $(\mathrm{FVCc})$ and the use of visible images to estimate the LAI and BM at early growth stages of wheat.

Concerning weed stand, the situation is different. The variability between the three replicates (Q1, Q2, and Q3) at each date is high for all the variables (high standard deviation in Figure 6b). These results reveal the strong spatial heterogeneity of the weeds, even in a micro-plot. FVCw is positively correlated with BM $\left(r^{2}=0.93\right)$. However, the linear correlation with LAI is fair $\left(r^{2}=0.44\right)$. The underestimation of LAI may be caused by the destructive approach (planimeter resolution, quantification errors) that is not adapted to small plants. 


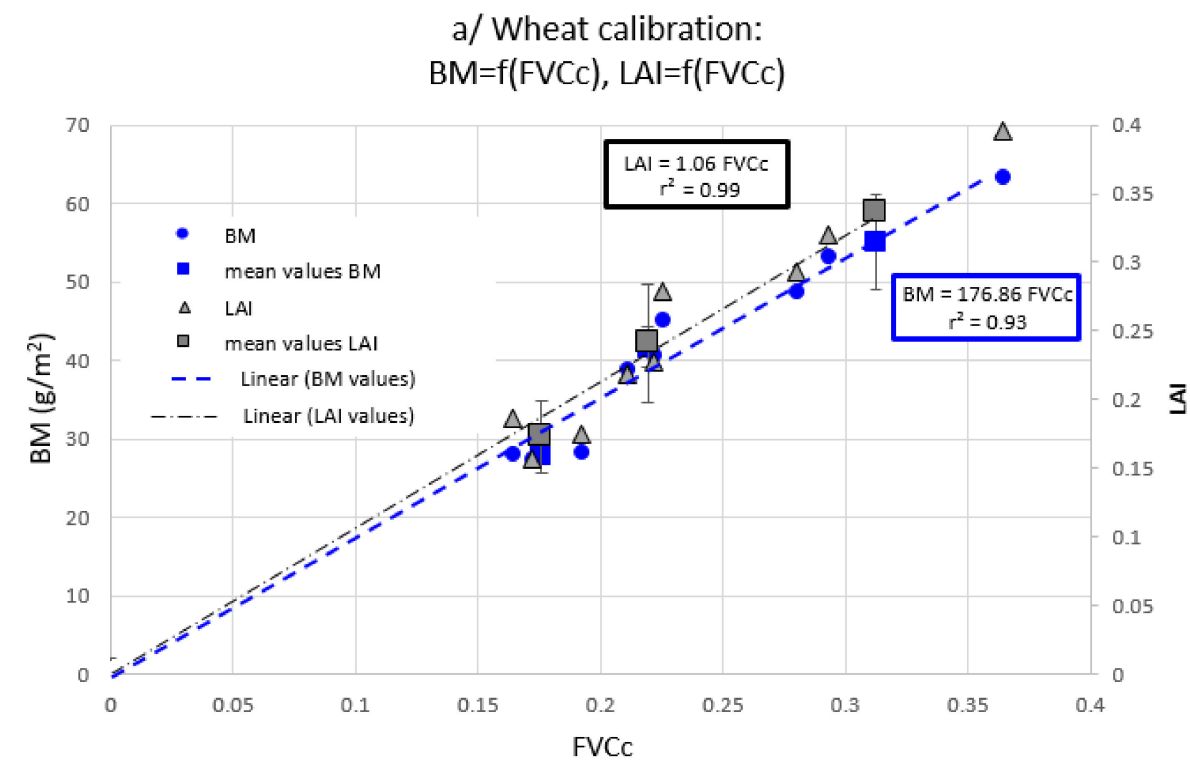

b/ Weed calibration:

$B M=f(F V C w), L A l=f(F V C w)$

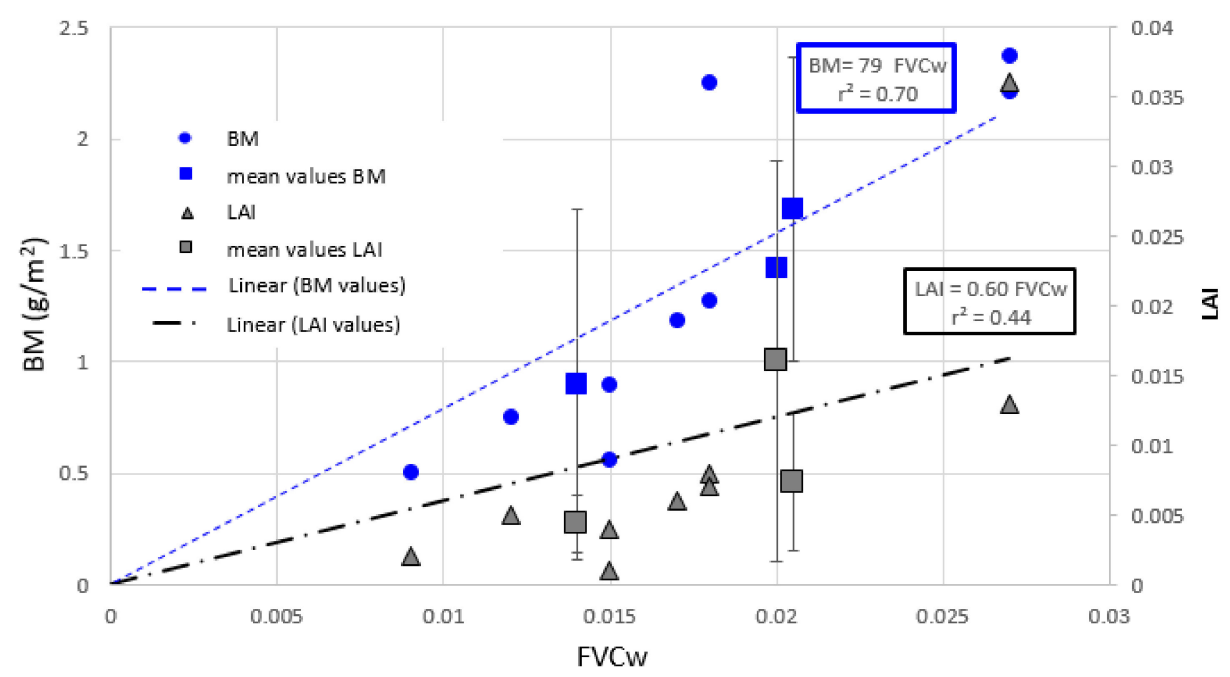

Figure 6. Linear regression between LAI and FVC (dashed black line) and between BM and FVC (dashed blue line) for (a) the wheat stand and (b) the weed stand. There were three replicates on each date. The squares represent the mean values and the bars the standard deviations.

Figure 7a presents the output map of $\delta B M c$ deduced from FVCc. Here again, it is built by a simple linear interpolation of the values deduced from each of the 254 images acquired on date 1 . The $\delta \mathrm{BMc}$ values are calculated from Equation (5). Then the $\delta \mathrm{BMc}$ map is divided into three clusters (Figure $7 \mathrm{~b}$ ) depending of the distribution values clusters (Figure $7 \mathrm{c})$ : the lower values $(\delta \mathrm{BMc}<0)$ that represent $25 \%$ of the pixels indicate that the crop biomass is higher than the reference value $\left(\mathrm{BM}_{r e f}\right)$, the intermediate values $(\delta \mathrm{BMc} \sim 0)$ that represent $61 \%$ of the pixels correspond to a normal crop growth. Finally, the highest values $(\delta B M c>0)$ that represent $14 \%$ of the pixels indicate a problem of crop growth probably caused by stress condition (i.e., weed, disease, pest, ... ). However, with this map deduced from visible images, we clearly identify the local problem of wheat growth but it is not possible to conclude about the origin of the stress. Combining the two $\delta \mathrm{BMc}$ with WP, it allows understanding the role played by weeds in the decrease of wheat growth. 


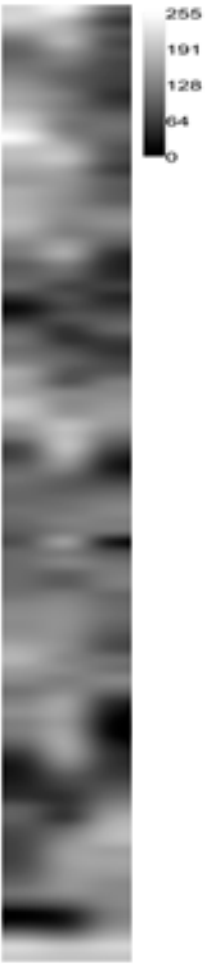

(a)

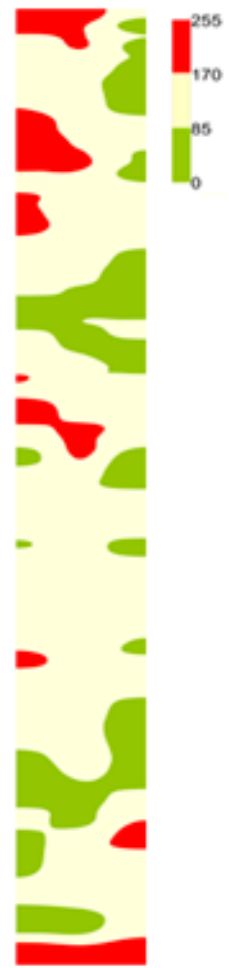

(b)
Distribution of $\delta B M c$ values

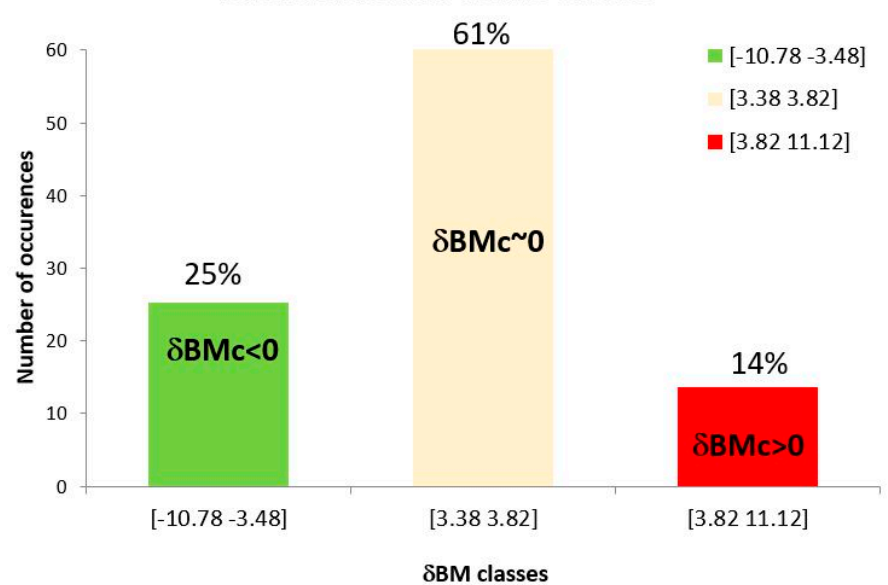

(c)

Figure 7. Date 1: (a) Wheat biomass (BMc) deduced from the FVCc map; (b) $\delta$ BMc map; (c) Distribution of $\delta$ BMc values.

\subsection{Comparison of $\delta B M c$ and WP Maps}

The two maps are compared on date 1 (Figure 8 ). The overlay is presented to help interpret the causes of a wheat stress related to weeds. One can note that the crop grow is generally good ( $\delta \mathrm{BMc}<0$ or close to zero) and WP is low to medium. This indicates an unstressed field crop. Under stress $(\delta B M c>0$, red spots in Figure 8a), we observe various situations depending on the location. We divided the plot into three regions associated to the three sampling dates. In the upper region, high $\delta \mathrm{BMc}$ values are located where WP is high or medium. For high WP values, that seems to indicate that the weeds are the main source of stress and that they compete with the crop. Nevertheless, for medium WP values, it is very likely that the crop stress originates from a combination of several stresses. In the central region, $\delta \mathrm{BMc}$ is high while WP is medium. Furthermore, when WP is low or medium, wheat growth does not seem to be affected. This is consistent with the literature [69] that mentions that some weed species observed on date 2 have low to moderate negative impact on crops [70]. Therefore, the critical problems on wheat growth in this region are due to weeds but also to other stressors, which have been not characterized. The lower region is similar to the upper region. The only weed observed on date 1 is Silphium perfoliatum L. (Asteraceae), a tall perennial plant that can negatively affect wheat growth depending on its size [71].

To sum up, the combination of the results of the two non-destructive indicators (WP and $\delta \mathrm{BMc}$ ), allows evaluating the crop-weed competition at specific date and determining when weeds have a dominant effect compared to other stressors. To go further, it would be necessary to look at the overall evolution of the field on different dates. A more effective method will be to explore in the near future using a UAV. 


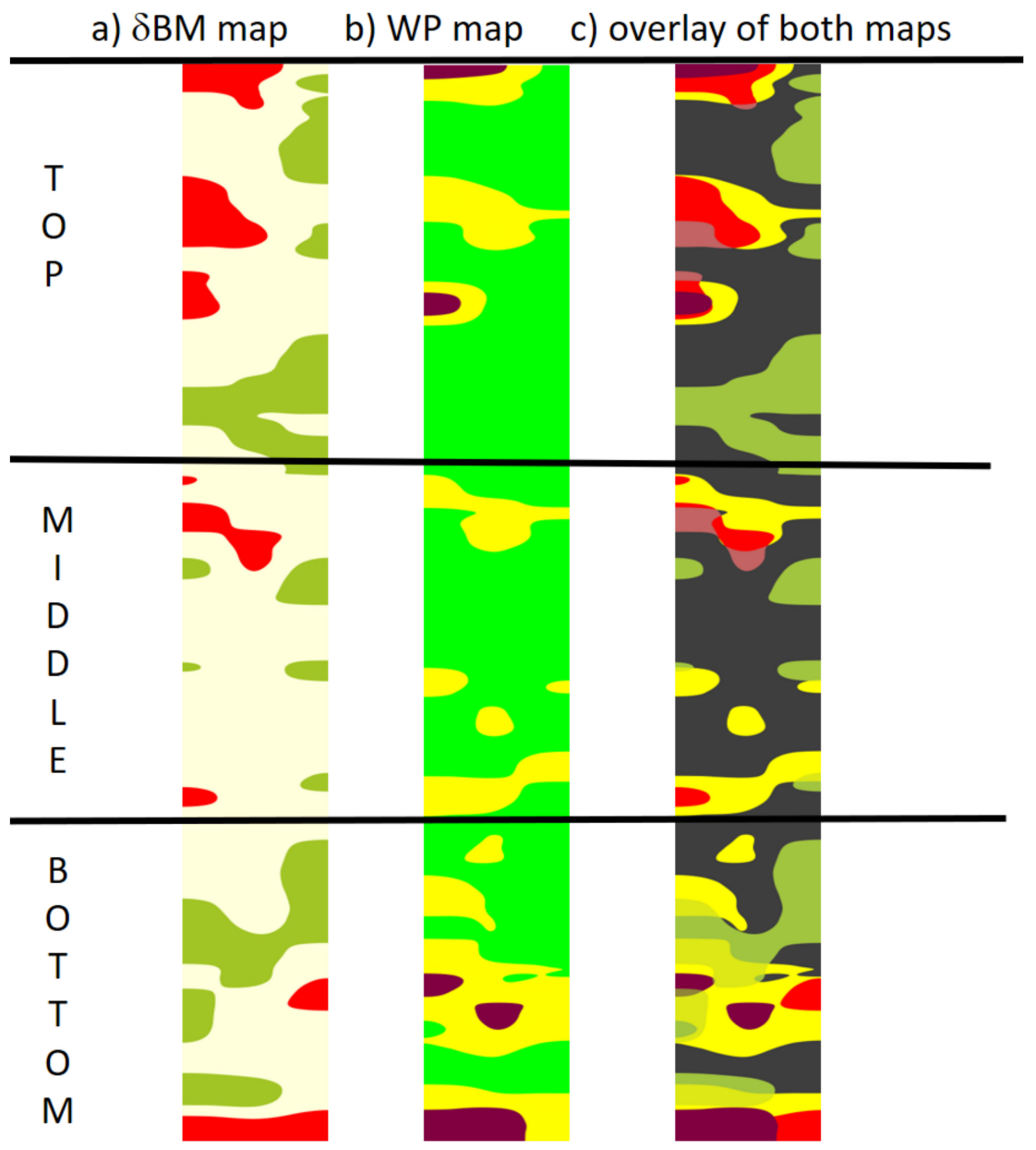

Figure 8. Date 1: (a) $\delta \mathrm{BM}$ map; (b) WP map; (c) Comparison between the two maps.

\section{Discussion}

\subsection{Relationship between Wheat Stress and Weed Pressure}

The combination of the $\delta \mathrm{BMc}$ and WP maps provides useful information for crop and weed management. Visible images can be used to monitor weed competition during crop growth with non-destructive and proximal sensing technologies in the early growth stages. However, proposing weed decision rules that address the evaluation of a crop agronomic risk remains a challenge at this stage of work. A more detailed analysis about weed species is required. These results must be treated with caution and experiments need to be carried out on a larger scale, looking at the yield loss depending on weed species. These experiments can be related to the ecophysiological model that predicts the wheat growth (e.g., AZODYN, [64]) and calculates the dry biomass of the aerial plant organs at a daily time-step during the vegetative phase under no stress conditions. Updates can then be made regularly during wheat growth simulation with these remote or proximal sensing data to optimize the site-specific weed management. To go further in long-term agro-ecological weed management, different combinations of cropping techniques should be explored and their long-term effects be assessed. One solution is the modeling approach. FlorSys is to date the only model that quantifies cropping system effects in interaction with pedoclimate on a multi-specific weed flora. It is a mechanistic "virtual field" model simulating daily weed and crop growth and reproduction over the years, on which arable cropping systems can be experimented in temperate climates [72]. However, like any model, it requires experimental data that will serve either as input variables or to validate the 
model predictions. Thus, our field trials will not only help the farmer in the daily management of his plots, but also the modelers.

\subsection{Temporal Evolution of Weed Harmfulness}

Up to now, weed competition in crop field has been addressed through weed density (plants $/ \mathrm{m}^{2}$ ) considered as one of the most important factors [59,71]. However, in the 1990s, some authors [73] suggested to study other relevant variables based on the contribution of weed species to the total leaf area index to describe the competition between crop and weeds. They were named the relative leaf area of the weed, the fractional vertical cover, or the weed coverage [73-76]. They can be deduced from imagery $[37,38]$. To investigate the substitution of destructive measurements to image-derived parameter, Figure 9 compares WP to the BMw/BMc ratio for accurate weed and crop monitoring. As far as the biomass $[36,77]$ is concerned, $\mathrm{BMw} / \mathrm{BMc}$ ratio is one of the closest indicators to the concept of direct primary harmfulness [78-80]. In this figure, the time evolution of these two ratios is compared over the three dates. Therefore, on each date, the BMw/BMc ratio behaves like WP on average and both ratios decrease over time. However, some differences are locally observed, especially for the quadrats $Q_{3}$ and $Q_{6}$ where high $B M w / B M c$ ratio (and particularly high $B M w$ value) is observed while WP is low (Table A2, Appendix A). A detailed analysis about the weeds observed in the quadrat $Q_{3}$, indicates the presence of a tall unusual plant, Silphium perfoliatum L., which may explain the difference between $\mathrm{BMw}$ and $\mathrm{FVCw}$. Concerning the quadrat $\mathrm{Q}_{6}, \mathrm{FVCw}$ is low compared to the $\mathrm{BMw}$, with small weed plants having a moderate density ( 35 plants $/ \mathrm{m}^{2}$ ). It mainly concerns Senecio vulgaris L. (SENVU), Polygonum aviculare L. (POLAV), and Fallopia convolvulus L. (POLCO) that have small leaves, low FVCw values, and high $\mathrm{BMw}$ values. Then, one observes on the quadrat $\mathrm{Q}_{4}$ that the $\mathrm{BMw} / \mathrm{BMc}$ is lower than WP. This low ratio can be explained by low BMc and BMw values. To sum up, even if we can substitute WP with $\mathrm{BMw} / \mathrm{BMc}$ at the plot scale, we must be cautious at the local scale where some singularities are observed and need to be clarify before generalizing the method.

\section{(BMw/BMc) vs WP}

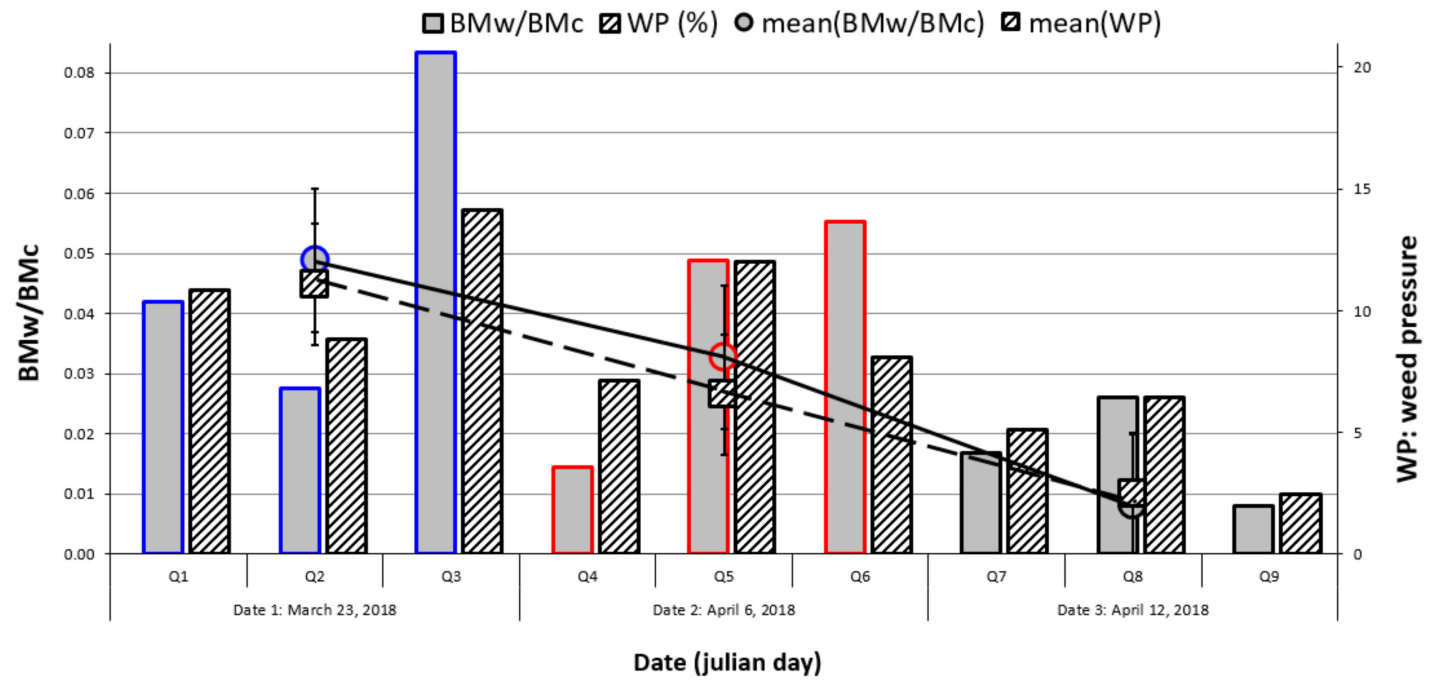

Figure 9. Comparison of the temporal evolution of the BMw/BMc ratio deduced from destructive measurements to WP derived from visible images. The average values (circle mark for BM and square for FVC) and the local values are obtained for each quadrat on the three dates.

\section{Conclusions}

The development of proximal sensing techniques allows exploring new strategies of weed management for sustainable agriculture practices. High-resolution imaging systems help to discriminate 
between crop and weeds by generating weed cover maps for a site-specific herbicide application. The next challenge of precision farming is to move towards the use of no herbicides in agriculture, which requires a better understanding of the crop-weed competition.

This article focused on the implementation of automatic weed detection using RGB images in order to generate maps of two indicators, the weed pressure and the wheat biomass production. Thanks to the performance of the SVM-RBF classification, using a bag of visual word vectors as inputs, the fractional vegetation cover (FVC) of both plants was determined. Beyond a simple location map, the weed pressure map described the competition between the crop and the weeds. Concerning wheat, the fractional vegetation cover (FVC) deduced from visible images provided a reliable proxy for LAI and BM measurements We also generated a map of $\delta \mathrm{BMc}$ that estimates the local wheat above-ground biomass production, informing about a possible stress. The combination of these two indicators shows that wheat stress is not always correlated to a high weed pressure. Although these results were obtained on a small plot, they are very promising. They provide a useful basis for accurate weed monitoring but they need to be confirmed in agricultural fields using UGV or UAV platforms, for example. In the future, we will develop a decision support tool for the monitoring of weeds while controlling wheat growth from indirect measurements of LAI and BM at early growth stages.

Author Contributions: C.G. conceived, designed and performed the experiments; C.G. and E.D. analyzed the data; E.D. performed image processing; All authors have read and agreed to the published version of the manuscript.

Funding: This research received no external funding.

Acknowledgments: Many thanks to the technicians, Vincent Durey and Annick Matéjicek, who were involved in this project, one on PAR sensor control and the other for plant identification.

Conflicts of Interest: The authors declare no conflict of interest. The funders had no role in the design of the study; in the collection, analyses, or interpretation of data; in the writing of the manuscript, or in the decision to publish the results.

\section{Abbreviations}

\section{Abbreviation \\ RGB image}

Above-ground BM

$\mathrm{BMw} / \mathrm{BMc}$

FVC, FVCc, FVCw

WP indicator

$\delta$ BMc indicator

\section{Description}

Red Green Blue image: visible image.

The Leaf Area Index (LAI expressed in $\mathrm{m}^{2} \cdot \mathrm{m}^{-2}$ ) is defined as the total area of the upper surfaces of the leaves contained in a volume above a square metre of soil area. It is determined destructively using a planimeter. It is a key variable used for physiological and functional plant models and by remote sensing models at large scale The dry matter biomass of aerial plant parts (BM expressed in $\mathrm{g} \cdot \mathrm{m}^{-2}$ ) is obtained by weighing plants after oven drying at $80^{\circ} \mathrm{C}$ for $48 \mathrm{~h}$. It is a key parameter for vegetation growth models playing a major role in photosynthesis and ecosystem functioning. The ratio between weeds and crop biomass, deduced from destructive measures, is one of the closest indicators to the concept of direct primary harmfulness.

Fractionnal Vegetation Cover is a parameter deduced from image. It corresponds to a vertical projection of plant foliar area. It represents the ratio of the number of pixels of vegetation to the total number of pixels in the image. FVCc and FVCw are the fraction of the soil covered by 'crop' or 'weed' type vegetation. Capturing vertical images allows comparing the FVC with the LAI and BM at early plant growth stages.

Weed Pressure defined as FVCw/FVCc ratio. It is deduced from image parameters and it represents the balance of power between crop and weeds.

It is defined as the difference between $\mathrm{BM}_{r e f}$, the mean value of wheat above-ground biomass in the field, and $\mathrm{BM}_{o b s}$. It is an evaluation of the local wheat above-ground biomass production. A local excess of wheat above-ground biomass is observed when $\mathrm{BM}_{o b s}>\mathrm{BM}_{r e f}$ whereas a stress is observed when $\mathrm{BM}_{o b s}<\mathrm{BM}_{r e f}$ 


\section{Abbreviation}

SVM-RBF classifier

SLIC algorithm

SURF algorithm

BoVW model

$\mathrm{TP} / \mathrm{FP} / \mathrm{PN} / \mathrm{FN}$

\section{Appendix A}

\section{Description}

Support Vector Machine with a Radial Basis Function kernel. It allows classifying data that is not at all linearly separable. A two-class classification (crop and weeds) is used and classifier input data are the BoVW vectors containing the main features for each observable (i.e., crop, weed).

Simple Linear Iterative Clustering algorithm. It is a fast and robust algorithm to segment image by clustering pixels based on their color similarity and proximity in the image. Thus, it generates superpixels that are more meaningful and easier to analyze. In our study, the superpixels of vegetation (128px x 128px) are then called 'thumbnails' and used to create the training data set (5000 labelled thumbnails per class). From this technique, we increase the number of labelled images of training set.

Speeded-Up Robust Features algorithm. It is a fast descriptor algorithm used for object detection and recognition. It is a robust algorithm in a scale and in-plane rotation invariant. SURF descriptors are used to recognize vegetation features. Thousands of features of each stand (crop and weeds) are extracted to construct a 500-dimensional BoVW vectors.

Bag of Visual Words (BoVW) model considers image features as words. In image classification, a bag of visual words is a frequency vector, called the "bag of visual words", which counts the number of unique relations between the features of an image to the visual dictionary. The visual dictionary is generated aggregating extracted features (500). Parameters deduced from confusion matrix to evaluate the performance of the supervised learning classifier (SVM-RBF)TP: true positive/FP: false positive/TN: true negative/FN: false negative

Table A1. Main Parameters of RGB Camera (Canon EOS 450D).

\begin{tabular}{cc}
\hline Specification & Value \\
\hline Geometric resolution $(\mathrm{px})$ & $4272 \times 2848$ \\
\hline CMOS sensor size $(\mathrm{mm})$ & $22.2 \times 14.8$ \\
\hline Megapixels & 12.2 \\
\hline Focal length $(\mathrm{mm})$ & 35 \\
\hline
\end{tabular}

Table A2. Summary of the values of the various parameters obtained by the image approach and the destructive approach for each of the three dates, 23 March, 6 April and 12 April. (FVCc: crop fractional vegetation cover; FVCw: weed fractional vegetation cover; LAI: leaf aera index).

\begin{tabular}{|c|c|c|c|c|c|c|c|c|}
\hline \multirow{3}{*}{2} & & \multicolumn{2}{|c|}{ Image Approach } & \multicolumn{5}{|c|}{ Destructive Approach } \\
\hline & 18 & \multirow{2}{*}{$\begin{array}{l}\text { Wheat } \\
\text { FVCc }\end{array}$} & \multirow{2}{*}{$\begin{array}{l}\text { Weeds } \\
\text { FVCw }\end{array}$} & \multicolumn{2}{|c|}{ Wheat } & \multicolumn{3}{|c|}{ Weeds } \\
\hline & & & & LAI & BMc $\left(\mathrm{g} . \mathrm{m}^{-2}\right)$ & LAI & BMc $\left(\right.$ g.m $\left.m^{-2}\right)$ & Plants.m ${ }^{-2}$ \\
\hline \multirow{3}{*}{ March 23} & Quadrat 1 & 0.157 & 0.034 & 0.187 & 28.2 & 0.006 & 1.184 & 67 \\
\hline & Quadrat 2 & 0.17 & 0.015 & 0.157 & 27.4 & 0.005 & 0.754 & 23 \\
\hline & Quadrat 3 & 0.184 & 0.026 & 0.175 & 28.4 & 0.036 & 2.369 & 76 \\
\hline \multirow{3}{*}{ April 6} & Quadrat 4 & 0.211 & 0.014 & 0.218 & 39 & 0.001 & 0.564 & 44 \\
\hline & Quadrat 5 & 0.225 & 0.027 & 0.279 & 45.2 & 0.013 & 2.211 & 58 \\
\hline & Quadrat 6 & 0.222 & 0.017 & 0.227 & 10.8 & 0.008 & 2.251 & 35 \\
\hline \multirow{3}{*}{ April 12} & Quadrat 7 & 0.293 & 0.015 & 0.32 & 53.3 & 0.004 & 0.898 & 84 \\
\hline & Quadrat 8 & 0.28 & 0.018 & 0.293 & 48.7 & 0.007 & 1.272 & 70 \\
\hline & Quadrat 9 & 0.364 & 0.009 & 0.395 & 63.28 & 0.002 & 0.503 & 61 \\
\hline
\end{tabular}



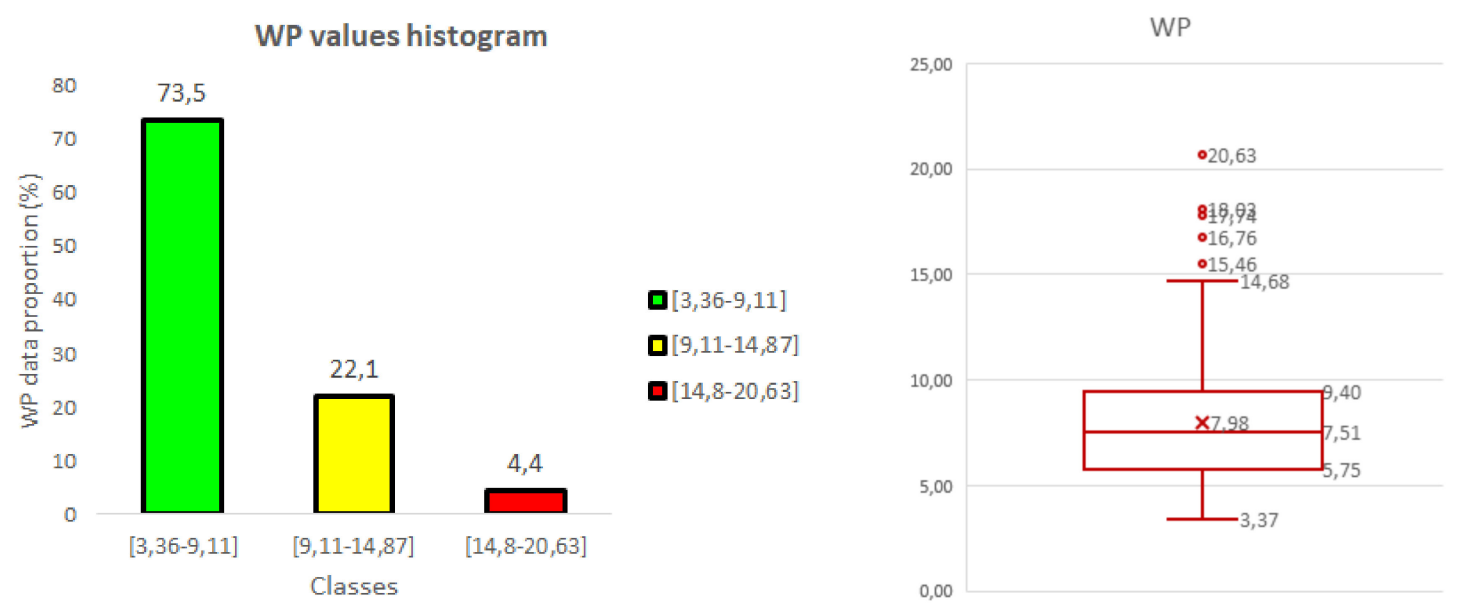

Figure A1. WP value distribution (left) and corresponding box-plot (right).

\section{References}

1. Christensen, S.; Heisel, T.; Walter, A.M.; Graglia, E. A decision algorithm for patch spraying. Weed Res. 2003, 43, 276-284. [CrossRef]

2. Maes, W.H.; Steppe, K. Perspectives for remote sensing with unmanned aerial vehicles in precision agriculture. Trends Plant Sci. 2019, 24, 152-164. [CrossRef] [PubMed]

3. Bàrberi, P. Weed management in organic agriculture: Are we addressing the right issues. Weed Res. 2002, 42, 177-193. [CrossRef]

4. Preston, C. Plant biotic stress: Weeds. Encycl. Agric. Food Syst. 2014, 343-348. [CrossRef]

5. Winifred, E.; Brenchley, W.E. The effect of weeds upon cereal crops. New Phytol. 1917, 16, 53-76.

6. López-Granados, F. Weed detection for site-specific weed management: Mapping and real-time approaches. Weed Res. 2011, 51, 1-11. [CrossRef]

7. Bawden, O.; Kulk, J.; Russell, R.; McCool, C.; English, A.; Dayoub, F.; Perez, T. Robot for weed species plant-specific management. J. Field Robot. 2017, 34, 1179-1199. [CrossRef]

8. Pflanz, M.; Nordmeyer, H.; Schirrmann, M. Weed Mapping with UAS Imagery and a Bag of Visual Words Based Image Classifier. Remote Sens. 2018, 10, 1530. [CrossRef]

9. Peña, J.M.; Torres-Sánchez, J.; de Castro, A.I.; Kelly, M.; López-Granados, F. Weed mapping in early-season Maize fields using object-based analysis of unmanned aerial vehicle (UAV) images. PLoS ONE 2013, 8, e77151. [CrossRef]

10. Louargant, M.; Jones, G.; Faroux, R.; Maillot, T.; Gée, C.; Villette, S. Unsupervised classification algorithm for early weed detection in row-crops by combining spatial and spectral information. Remote Sens. 2018, 10, 761. [CrossRef]

11. De Castro, A.I.; Torres-Sánchez, J.; Peña, J.M.; Jiménez-Brenes, F.M.; Csillik, O.; López-Granados, F. An automatic Random Forest-OBIA Algorithm for Early Weed Mapping between and within Crop Rows Using UAV Imagery. Remote Sens. 2018, 10, 285. [CrossRef]

12. Huang, H.; Deng, J.; Lan, Y.; Yang, A.; Deng, X.; Zhang, L. A fully convolutional network for weed mapping of unmanned aerial vehicle (UAV) imagery. PLoS ONE 2018, 13, e0196302. [CrossRef] [PubMed]

13. López-Granados, F.; Torres-Sánchez, J.; Serrano-Pérez, A.; De Castro, A.I.; Mesas-Carrascosa, F.J.; Peña, J.-M. Early season weed mapping in sunflower using UAV technology: Variability of herbicide treatment maps against weed thresholds. Precis. Agric. 2016, 17, 183-199. [CrossRef]

14. Woebbecke, D.M.; Meyer, G.E.; Von Bargen, K.; Mortensen, D.A. Color indices for weed identification under various soil, residue, and lighting conditions. Trans. ASAE 1995, 38, 259-269. [CrossRef]

15. Torres-Sánchez, J.; Peña, J.; de Castro, A.; López-Granados, F. Multi-temporal mapping of the vegetation fraction in early-season wheat fields using images from UAV. Comput. Electron. Agric. 2014, 103, 104-113. [CrossRef] 
16. Meyer, G.E.; Neto, J.C. Verification of color vegetation indices for automated crop imaging applications. Comput. Electron. Agric. 2008, 63, 282-293. [CrossRef]

17. Rouse, J.; Haas, R.; Schell, J.; Deering, D. Monitoring vegetation systems in the Great Plains with ERTS. In Third Earth Resources Technology Satellite-1 Symposium -Volume I: Technical Presentations; NASA: Washington, DC, USA, 1974; p. 309.

18. Tang, L.; Tian, L.; Steward, B.L. Classification of broadleaf and grass weeds using Gabor wavelets and an artificial neural network. Trans. ASAE 2003, 46, 1247-1254. [CrossRef]

19. Gée, C.; Guillemin, J.P.; Bonvarlet, L.; Magnin-Robert, J.B. Weeds classification based on spectral properties. In Proceedings of the 7th International Conference on Precision Agriculture and Others Resources Management, Minneapolis, MN, USA, 24-28 July 2004.

20. Pérez-Ortiz, M.; Peña, J.M.; Gutiérrez, P.A.; Torres-Sánchez, J.; Hervás-Martínez, C.; López-Granados, F. Selecting patterns and features for between- and within- crop-row weed mapping using UAV imagery. Expert Syst. Appl. 2016, 47, 85-94. [CrossRef]

21. Akbarzadeh, S.; Paap, A.; Ahderom, S.; Apopei, B.; Alameh, K. Plant discrimination by Support Vector Machine classifier based on spectral reflectance. Comput. Electron. Agric. 2018, 148, 250-258. [CrossRef]

22. Henrique Yano, I. Weed identification in sugarcane plantation through images taken from remotely piloted aircraft (RPA) and kNN classifier. J. Food Nutr. Sci. 2017, 5, 211. [CrossRef]

23. Guerrero, J.; Pajares, G.; Montalvo, M.; Romeo, J.; Guijarro, M. Support vector machines for crop/weeds identification in maize fields. Expert Syst. Appl. 2012, 39, 11149-11155. [CrossRef]

24. Garcia-Ruiz, F.J.; Wulfsohn, D.; Rasmussen, J. Sugar beet (Beta vulgaris L.) and thistle (Cirsium arvensis L.) discrimination based on field spectral data. Biosyst. Eng. 2015, 139, 1-15. [CrossRef]

25. Pérez-Ortiz, M.; Pena, J.M.; Gutiérrez, P.A.; Torres-Sánchez, J.; Hervás-Martínez, C.; López-Granados, F. A semi-supervised system for weed mapping in sunflower crops using unmanned aerial vehicles and a crop row detection method. Appl. Soft Comput. J. 2015, 37, 533-544. [CrossRef]

26. Bah, M.D.; Hafiane, A.; Canals, R. Deep Learning with unsupervised data labeling for weeds detection on UAV images. Remote Sens. 2018, 10, 1690. [CrossRef]

27. Suh, H.K.; Hofstee, J.W.; IJsselmuiden, J.; Van Henten, E.J. Sugar beet and volunteer potato classification using Bag-of-Visual-Words model, Scale-Invariant Feature Transform, or Speeded Up Robust Feature descriptors and crop row information. Biosyst. Eng. 2018, 166, 210-226. [CrossRef]

28. Castillejo-González, I.L.; Peña-Barragán, J.M.; Jurado-Expósito, M.; Mesas-Carrascosa, F.J.; López-Granados, F. Evaluation of pixel- and object-based approaches for mapping wild oat (Avena sterilis) weed patches in wheat fields using QuickBird imagery for site-specific management. Eur. J. Agron. 2014, 59, 57-66. [CrossRef]

29. Baio, F.H.R.; Neves, D.C.; Souza, H.B.; Leal, A.J.F.; Leite, R.C.; Molin, J.P.; Silva, S.P. Variable rate spraying application on cotton using an electronic flow controller. Precis. Agric. 2018, 19, 912-928. [CrossRef]

30. Pandey, P.; Irulappan, V.; Bagavathiannan, M.V.; Senthil-Kumar, M. Impact of combined abiotic and biotic stresses on plant growth and avenues for crop improvement by exploiting physio-morphological Traits. Front. Plant Sci. 2017, 8, 537. [CrossRef]

31. Buhler, D.D. Development of Alternative Weed Management Strategies. J. Prod. Agric. 1996, 9, 501-505. [CrossRef]

32. Van Evert, F.K.; Fountas, S.; Jakovetic, D.; Crnojrvic, V.; Travlos, I.; Kempenaar, C. Big Data for weed control and crop protection. Weed Res. 2017, 57, 218-233. [CrossRef]

33. Chason, J.W.; Baldocchi, D.D.; Huston, M.A. A comparison of direct and indirect methods forestimating forest canopy leaf area. Agric. For. Meteorol. 1991, 57, 107-128. [CrossRef]

34. Fuentes, S.; Palmer, A.R.; Taylor, D.; Zeppel, M.; Whitley, R.; Eamus, D. An automated procedure for estimating the leaf area index (LAI) of woodland ecosystems using digital imagery, MATLAB programming and its application to an examination of the relationship between remotely sensed and field measurements of LAI. Funct. Plant. Biol. 2008, 35, 1070-1079. [CrossRef] [PubMed]

35. Pekin, B.; Macfarlane, C. Measurement of crown cover and leaf area index using digital cover photography and its application to remote sensing. Remote Sens. 2009, 1, 1298-1320. [CrossRef]

36. Colbach, N.; Cordeau, S. Reduced herbicide use does not increase crop yield loss if it is compensated by alternative preventive and curative measures. Eur. J. Agron. 2018, 94, 67-78. [CrossRef]

37. Lotz, L.A.P.; Kropff, M.J.; Wallinga, J.; Bos, H.J.; Groeneveld, R.M.W. Techniques to estimate relative leaf area and cover of weeds in crops for yield loss prediction. Weed Res. 1994, 34, 167-175. [CrossRef] 
38. Rasmussen, J.; Norremark, M.; Bibby, B.M. Assessment of leaf cover and crop soil cover in weed harrowing research using digital images. Weed Res. 2017, 47, 199-310. [CrossRef]

39. Casadesús, J.; Villegas, D. Conventional digital cameras as a tool for assessing leaf area index and biomass for cereal breeding. J. Integr. Plant. Biol. 2014, 56, 7-14. [CrossRef]

40. Huete, A.R. A soil vegetation adjusted index (SAVI). Int J. Remote Sens. 1988, 25, 295-309. [CrossRef]

41. Baret, F.; Guyot, G. Potentials and limits of vegetation indices for LAI and APAR assessment. Remote Sens. Environ. 1991, 35, 161-173. [CrossRef]

42. Carlson, T.N.; Ripley, D.A. On the relation between NDVI, fractional vegetation cover, and leaf area index. Remote Sens. Environ. 1997, 62, 241-252. [CrossRef]

43. Royo, C.; Villegas, D. Field Measurements of Canopy Spectra for Biomass Assessment of Small-Grain Cereals. In Production and Usage; Matovic, D., Ed.; Biomass: Rijeka, Croatia, 2011.

44. Casadesús, J.; Villegas, D. Simple digital photography for assessing biomass and leaf area index in cereals. Bio Protoc. 2015, 5, e1488.

45. Beniaich, A.; Naves Silva, M.L.; Pomar Avalos, F.A.; de Duarte Menezes, M.; Moreira Cândido, B. Determination of vegetation cover index under different soil management systems of cover plants by using an unmanned aerial vehicle with an onboard digital photographic camera. Psemina Ciencias Agrar. 2019, 40, 49-66. [CrossRef]

46. Guo, W.; Rage, U.K.; Ninomiya, S. Illumination invariant segmentation of vegetation for time series wheat images based on decision tree model. Comput. Electron. Agric. 2013, 96, 58-66. [CrossRef]

47. Yang, W.; Wang, S.; Zhao, X.; Zhang, J.; Feng, J. Greenness identification based on HSV decision tree. Inf. Process. Agric. 2015, 149-160. [CrossRef]

48. Burgos-Artizzu, X.P.; Ribeiro, A.; Guijarro, M.; Pajares, G. Real-time image processing for crop/weed discrimination in maize fields. Comput. Electron. Agric. 2011, 75, 337-346. [CrossRef]

49. Kataoka, T.; Kaneko, T.; Okamoto, H.; Hata, S. Crop growth estimation system using machine vision. In Proceedings of the Advanced Intelligent Mechatronics, Kobe, Japan, 20-24 July 2003; pp. 1079-1083.

50. Marchant, J.A.; Onyango, C.M. Shadow invariant classification for scenes illuminated by daylight. J. Opt. Soc. Am. 2000, 17, 1952-1996. [CrossRef]

51. Bay, H.; Ess, A.; Tuytelaars, T.; Van Gool, L. Speeded-Up Robust Features (SURF). Comput. Vis. Image Und. 2008, 10, 346-359. [CrossRef]

52. Csurka, G.; Dance, C.; Fan, L.; Willamowski, J.; Bray, C. Visual categorization with bags of keypoints. In Workshop on Statistical Learning in Computer Vision; ECCV: Prague, Czech Republic, 2004; pp. 1-22.

53. Ma, J.; Ma, Z.; Kang, B.; Lu, K. A Method of Protein Model Classification and Retrieval Using Bag-ofVisual-Features. Comput. Math. Methods Med. 2014, 2014, 269394. [CrossRef] [PubMed]

54. Vapnik, V.; Chervonenkis, A. On the uniform convergence of relative frequencies of events to their probabilities. Probab. Appl. 1971, 16, 264-280. [CrossRef]

55. Ahmed, F.; Al-Mamun, H.A.; Bari, A.S.M.H.; Hossain, E.; Kwan, P. Classification of crops and weeds from digital images: A support vector machine approach. Crop. Prot. 2012, 40, 98-104. [CrossRef]

56. Sokolova, M.; Lapalme, G. A systematic analysis of performance measures for classification tasks. Inf. Process. Manag. 2009, 45, 427-437. [CrossRef]

57. Cohen, J. A coefficient of agreement for nominal scales. Educ. Psychol. Meas. 1960, 20, 27-46. [CrossRef]

58. Merienne, J.; Larmure, A.; Gée, C. Digital tools for a biomass prediction from a plant-growth model. Application to a Weed Xontrol in Wheat Crop. In Proceedings of the European Conference on Precision Agriculture, Montpellier, France, 8-12 July 2019; Stafford, J.V., Ed.; Wageningen Academic: Montpellier, France, 2019; pp. 597-603.

59. Cousens, R. Theory and reality of weed control thresholds. Plant. Prot. Quart. 1987, 2, 13-20.

60. Gherekhloo, J.; Noroozi, S.; Mazaheri, D.; Ghanbari, A.; Ghannadha, M.R.; Vidal, R.A.; de Prado, R.V. Multispecies weed competition and their economic threshold on the wheat crop. Planta Daninha 2017, 28, 239-246. [CrossRef]

61. O'Donovan, J.T. Quack grass (Elytrigia repens) interference in Canola (Brassica compestris). Weed Sci. 1991, 39, 397-401. [CrossRef]

62. O'Donovan, J.T.; Blackhaw, R.E. Effect of volunteer barley (Hordeum vulgare L.) interference on field pea (Pisum sativum L.) yield and profitability. Weed Sci. 1997, 42, 249-255. 
63. Wells, G.J. Annual weed competition in wheat crops: The effect of weed density and applied nitrogen. Weed Res. 1979, 19, 185-191. [CrossRef]

64. Jeuffroy, M.H.; Recous, S. Azodyn: A simple model simulating the date of nitrogen deficiency for decision support in wheat fertilization. Eur. J. Agron. 1999, 10, 129-144. [CrossRef]

65. Aase, J.K. Relationship between leaf area and dry matter in winter wheat. Agron. J. 1978, 70, 563-565. [CrossRef]

66. Golzarian, M.R.; Frick, R.A.; Rajendran, K.; Berger, B.; Roy, S.; Tester, M.; Lun, S.D. Accurate inference of shoot biomass from high-throughput images of cereal plants. Plant. Methods 2011, 7, 2. [CrossRef]

67. Neilson, E.H.; Edwards, A.M.; Blomstedt, C.K.; Berger, B.; Moler, B.M.; Gleadow, R.M. Utilization of a high-throughput shoot imaging system to examine the dynamic phenotypic responses of a $\mathrm{C} 4$ cereal crop plant to nitrogen and water deficiency over time. J. Exp. Bot. 2015, 66, 1817-1832. [CrossRef] [PubMed]

68. Chen, D.; Shi, R.; Pape, J.M.; Neumann, K.; Arend, D.; Graner, A.; Chen, M.; Klukas, C. Predicting plant biomass accumulation from image-derived parameters. Giga Sci. 2018, 7, 1-13. [CrossRef] [PubMed]

69. Valantin-Morison, M.; Guichard, L.; Jeuffroy, M.H. Comment maîtriser la flore adventice des grandes cultures à travers les éléments de l'itinéraire technique. Innov. Agron. 2008, 3, $27-41$.

70. Welbank, P.J. A comparison of competitive effects of some common weed species. Ann. Appl. Biol. 1963, 51, 107-125. [CrossRef]

71. Gansberger, M.; Montgomery, L.F.R.; Liebhard, P. Botanical characteristics, crop management and potential of Silphium perfoliatum L. as a renewable resource for biogas production: A review. Ind. Crop. Prod. 2015, 63, 362-372. [CrossRef]

72. Colbach, N.; Collard, A.; Guyot, S.H.M.; Mézière, D.; Munier-Jolain, N. Assessing innovative sowing patterns for integrated weed management with a 3D crop: Weed competition model. Eur. J. Agron. 2014, 53, 74-89. [CrossRef]

73. Kropff, M.J.; Spitters, C.J.T. A simple model of crop loss by weed competition from early observations on relative leaf area of weeds. Weed Res. 1991, 31, 97-105. [CrossRef]

74. Thompson, J.F.; Stafford, J.V.; Miller, P.C.H. Potential for automatic weed detection and selective herbicide application. Crop. Prot. 1991, 10, 254-259. [CrossRef]

75. Lotz, L.A.P.; Kropff, M.J.; Wallinga, H.J.B. Prediction of yield loss based on relative leaf cover of weeds. In Proceedings of the First International Weed Control Congress, Melbourne, Australia, 17-21 February 1993; pp. 290-292.

76. Lutman, P.J.W. Prediction of the competitive effects of weeds on the yields of several spring-sown arable crops. In Proceedings of the IXeme Colloque International sur la Biologie des Mauvaises, ANPP, Paris, France, 16-18 September 1992; pp. 337-345.

77. Christensen, S. Crop weed competition and herbicide performance in cereal species and varieties. Weed Res. 1994, 34, 29-36. [CrossRef]

78. Caussanel, J.P. Nuisibilité et seuils de nuisibilité des mauvaises herbes dans une culture annuelle: Situation de concurrence bispécifique. Agron. J. 1989, 9, 219-240. [CrossRef]

79. Florez Fernandez, J.A.; Fischer, A.J.; Ramirez, H.; Duque, M.C. Predicting Rice Yield Losses Caused by Multispecies Weed Competition. Agron. J. 1999, 1, 87-92. [CrossRef]

80. Milberg, P.; Hallgren, E. Yield loss due to weeds in cereals and its large-scale variability in Sweden. Field Crop. Res. 2004, 86, 199-209. [CrossRef]

(C) 2020 by the authors. Licensee MDPI, Basel, Switzerland. This article is an open access article distributed under the terms and conditions of the Creative Commons Attribution (CC BY) license (http://creativecommons.org/licenses/by/4.0/). 